\title{
Si Boride-Coated Si Nanoparticles with Improved Thermal
}

\section{Oxidation Resistance}

Tae Kyoung Kim ${ }^{1,4}$, Jaeyun Moon ${ }^{1,4}$, Bryan VanSaders ${ }^{1,2,4}$, Dongwon Chun ${ }^{1,4}$, Calvin J. Gardner ${ }^{1,4}$, Jae-Young Jung ${ }^{1,4}$, Gang Wang ${ }^{3}$, Renkun Chen ${ }^{1,4}$, Zhaowei Liu $^{2}$, Yu Qiao ${ }^{3}$, and Sungho Jin ${ }^{1,4}$,

${ }^{1}$ Materials Science \& Engineering, ${ }^{2}$ Electrical \& Computer Engineering, ${ }^{3}$ Structural Engineering, and ${ }^{4}$ Mechanical and Aerospace Engineering, University of California at San Diego, 9500 Gilman Dr., La Jolla, CA 92093, USA

* Corresponding author : jin@ucsd.edu

\begin{abstract}
A new fabrication technique is devised to synthesize conformal Si core-shell nanoparticles (NPs) with Si boride nanoshell by reacting the surface atoms of Si NPs (50 200 nm diameter) with a molten salt of sodium borohydride. The shell layer, about 10 20 nm thick, consists of a mixture of crystalline phase $\left(\mathrm{SiB}_{\mathrm{x}}\right)$ and other amorphous phases as identified by TEM and EELS analysis. New absorbance peaks for Si - Si boride core-shell NPs appear at the wavenumber of 940 and $777 \sim 677 \mathrm{~cm}^{-1}$ in FT-IR analysis. TGA analysis reveals that the core-shell structured $\mathrm{Si}-\mathrm{Si}$ boride NPs exhibit a remarkably improved resistance to thermal oxidation by a factor of 4.6 at $750{ }^{\circ} \mathrm{C}$ and at by a factor of 3.5 at $850^{\circ} \mathrm{C}$ compared to bare Si. Optical measurements show that
\end{abstract}


spectrally selective coating (SSC) layers made of Si - Si boride NPs have a superior optical stability to that of the bare Si NPs after annealing at high temperature, and desirably exhibit a lower reflectance in the visible spectrum range than the bare Si NPs. These surface-protected, oxidation-resistant semiconductor materials and their novel fabrication methods exhibit further broad applicability of boride nanolayers which can be used for high temperature applications such as solar thermal power generation.

Keywords: silicon boride nanoshell, core-shell nanoparticles, sodium borohydride, thermal oxidation resistance, spectrally selective coating, solar thermal power generation.

\section{Introduction}

High performance semiconductor materials and metals have been required to develop for various cutting-edge applications including solar power systems, photoelectrochemical hydrogen generation systems, aerospace systems, and microelectronics [1-7]. Some of these applications involve high temperature operation, for instance, in solar thermal applications and aerospace systems. Especially, for solar absorbers in concentrating solar power (CSP) systems, it has been tried to find metals and semiconductor materials stable at high operation temperature which enables to achieve higher thermal efficiency due to Carnot cycle type processes involved [2]. As recently demonstrated, concentrating solar thermoelectric generator (CSTEG) also needs to make high temperature condition made by the absorbed sunlight to obtain better efficiency [8-10].

However, a high temperature operation of metals and semiconductor materials in air atmosphere can cause significant oxidation and the degradation of device performance. For instance, one of important semiconductor materials, silicon, grows a $32 \mathrm{~nm}$-thick oxide layer 
after annealing for $50 \mathrm{hrs}$ at $700{ }^{\circ} \mathrm{C}$ in dry oxygen [11]. Smaller particle sizes such as nanoparticles are desirable for enhanced sunlight absorption, but smaller particles are more susceptible to oxidation, especially at higher temperatures. Therefore, high performance materials resistant to thermal oxidation is necessary to be developed for the operation in air at elevated temperature, to achieve stable performance of systems.

The objective of this research is to design new types of surface-protected Si nanoparticles with improved oxidation resistance by means of a novel nanoshell-synthesizing method, which can be a prototype of oxidation-resistant core-shell nanoparticles used for the power system operated at high temperature. One candidate material for the passivation nanolayer is boride alloys which have been studied to apply for high temperature applications including a nuclear reactor and aerospace systems because of their good properties in the aspect of melting temperature, hardness, thermal shock resistance and oxidation resistance [12-14]. For this research, Si boride nanoshell was employed to make conformal coating on the surface of $\mathrm{Si}$ nanoparticles because $\mathrm{Si}$ borides such as $\beta-\mathrm{SiB}_{3}$ are known to exhibit superior resistance to thermal oxidation up to $1000{ }^{\circ} \mathrm{C}$ in air [15]. In addition, vitreous coatings as a tightly sealed antioxidation layer was also investigated to increase the oxidation resistance [16-19].

Silicon borides have been made by a few different kinds of method including fusion, sintering, reduction, chemical vapor deposition (CVD), and e-beam evaporation which synthesized ingot form and thin film of silicon bordes [20-26]. But these procedures for making Si-B alloys is difficult to be applied for the fabrication of a conformal Si boride nanoshell on the surface of Si nanoparticles because fusion and sintering process is profer for large-sized ingot and CVD or e-beam evaporation is the more appropriate method for forming thin films on substrates. 
We have therefore designed a novel process to create a conformal Si boride shell on the surface of Si nanoparticles, utilizing a molten salt of sodium borohydride $\left(\mathrm{NaBH}_{4}\right)$ as a boron source. Using this strategy, we have successfully fabricated such a protective boride nanolayer on Si nanoparticles, characterized the coated layer, and discussed its impact on oxidation resistance as well as optical reflection behavior.

\section{Materials and Methods}

\subsection{Synthesis of Si Boride NanoShell on the Surface of Si Nanoparticles}

Si nanoparticles ( $99.9 \%$ purity) with average particle size of $100 \mathrm{~nm}$ as a core material and $\mathrm{NaBH}_{4}$ ( 98 \% purity) powder as a boron source were purchased from Alfa Aesar (Ward Hill, MA). For sample preparations, the $\mathrm{Si}$ nanoparticles and $\mathrm{NaBH}_{4}$ powder were thoroughly mixed together by repeated grinding with a mortar and a pestle in a globe box under Ar atmosphere. A quartz tube was sealed with the mixed powders and Ar gas, and heat-treated at $500{ }^{\circ} \mathrm{C}$ for 2 days which enabled $\mathrm{NaBH}_{4}$ in the form of a molten salt to make a diffusional reaction with the surface atoms of Si nanoparticles to form a Si boride shell. After the reaction, the residual unreacted $\mathrm{NaBH}_{4}$ was dissolved away with de-ionized (DI) water, and the core-shell nanoparticles were collected with a centrifuge followed by freeze-drying. To crystallize Si boride nanoshell, an annealing process of $900{ }^{\circ} \mathrm{C} / 5 \mathrm{hrs}$ under Ar atmosphere was employed. After annealing, some portion of the shell remained amorphous. An additional shell-passivation process was applied at $550{ }^{\circ} \mathrm{C}$ for $1 \mathrm{hr}$ in an oxidizing atmosphere of air in order to convert the amorphous phase in the shell to a passivating borate phase (presumably a glassy borosilicate phase that would not oxidize further) as a part of the shell structure. Without this stabilizing heat treatment step, the oxidation resistance was inferior on high temperature exposure, which was observed with weight gain by 
thermo-gravimetric analysis (TGA). For the comparative phase analysis, $\mathrm{SiB}_{3}$ particles, and $\mathrm{SiB}_{6}$ particles were prepared by ball-milling of arc-melted metal ingots with the same stoichiometric compositions.

\subsection{Characterization of Core-Shell Structure}

The core-shell structure of the as-made Si - Si boride NPs was imaged with transmission electron microscope (TEM) (FEI Tecnai F30G2 Polara) operated at $300 \mathrm{kV}$ in bright field (BF) mode and high resolution (HR) mode, as shown in Figure 1(a). The scanning electron microscope (SEM) analysis was also carried out with the microstructure shown in Figure 1(b). The crystal structure of Si boride shell was analyzed after the annealing and shell-passivation procedure with TEM and a fast Fourier transform (FFT) analysis (see Figure 2).

The presence of boron in the shell layer of Si-Si boride NPs was confirmed by electron energy loss spectroscopy (EELS) with an approximate boron content estimated. For EELS analysis, the sample was imaged with TEM (FEI Tecnai TF-20 FEG) operated at 200kV in highangle annular dark-field (HAADF) scanning transmission electron microscope (STEM) mode. EELS line scanning was made in STEM mode using a nominal $1 \mathrm{~nm}$ electron beam and a Gatan Enfina DigiPEELS spectrometer (see Figure 3).

\subsection{FT-IR Analysis}

For the annealed Si-Si boride NPs and bare Si NPs, infrared absorbance measurement was performed using Fourier transform infrared spectroscopy (FT-IR) (Nicolet 6700 analytical MCT FT-IR Spectrometer) to observe the effect of Si boride shell on the IR absorbance behavior. And 
FT-IR analysis was also made for ball-milled $\mathrm{SiB}_{3}$, and $\mathrm{SiB}_{6}$ particles to be compared to $\mathrm{Si}-\mathrm{Si}$ boride NPs. The spectrum was scanned with the data spacing of $0.4 \mathrm{~cm}^{-1}$.

\subsection{Analysis of Thermal Oxidation Resistance}

For the $\mathrm{Si}$ - Si boride NPs, the thermal oxidation resistance was evaluated by measuring the total weight gain of particles during heating in a pure oxygen atmosphere with thermogravimetric analysis (TGA). Measurements were carried out at two different holding temperatures of $750^{\circ} \mathrm{C}$ and $850^{\circ} \mathrm{C}$. Samples were heated at a rate of $20^{\circ} \mathrm{C} / \mathrm{min}$ to the maximum temperatures and held there for $2 \mathrm{hrs}$.

\subsection{Optical Reflectance Measurement of SSC layers}

To compare optical reflectance of Si boride-coated Si NPs with bare Si NPs, spectrally selective coating (SSC) layers were prepared by drop-casting the prepared nanoparticles dispersed in ethanol onto Inconel ${ }^{\circledR} 625$ super alloy substrates, which are commonly used for metal tubes carrying heat transfer fluids inside and coated with the solar absorber materials outside the tubing in concentrating solar power systems. The thickness of the SSC layers made of the prepared nanoparticles was $\sim 100 \mu \mathrm{m}$ and the area of the coated region was $1 \mathrm{~cm}^{2}$. Visible/IR reflectance of SSC layers was measured, using a home-made optical measurement system consisting of an integration sphere (4" LabSphere ${ }^{\circledR}$, Spectraflect ${ }^{\circledR}$ coated) assembled with an Andor ${ }^{\circledR}$ Shamrock 303i spectrometer equipped with Si and InGaAs-based detectors. The reflectance was measured with incidence angle of $12.5^{\circ}$ in the spectrum range of $400 \sim 2000 \mathrm{~nm}$ at room temperature. In order to observe the effect of Si boride nanoshell on the stability of 
optical property at high temperature, the reflectance of SSC layers was also measured after both bare Si and Si-Si boride NPs were annealed at $850{ }^{\circ} \mathrm{C}$ for $5 \mathrm{hrs}$ and $10 \mathrm{hrs}$ in air.

\section{Results and Discussion}

\subsection{Shell Formation and Composition of Si-Si boride Core-Shell NPS}

Sodium borohydride $\left(\mathrm{NaBH}_{4}\right)$ powder material starts to melt at $400{ }^{\circ} \mathrm{C}$ to form a molten salt of $\mathrm{Na}^{+}\left[\mathrm{BH}_{4}\right]^{-}[27]$, followed by decomposition reactions at $450{ }^{\circ} \mathrm{C}$ into $\left[\mathrm{NaH}+\mathrm{B}+1.5 \mathrm{H}_{2}\right]$ or $\left[\mathrm{Na}+\mathrm{B}+2 \mathrm{H}_{2}\right][28]$. During the shell-forming procedure occurring when the temperature reaches $500{ }^{\circ} \mathrm{C}$, phases such as a molten salt phase, a decomposed gas phase $\left(\mathrm{H}_{2}\right)$ and solid phases can coexist. In this mixed-phase state at $500{ }^{\circ} \mathrm{C}$, boron atoms from $\mathrm{NaBH}_{4}$ can diffuse and react with $\mathrm{Si}$ atoms to form a desirable Si boride nanoshell on the surface of Si nanoparticles, which can serve as an oxidation-resistant protective layer.

Various structural and compositional analyses of the $\mathrm{NaBH}_{4}-$ reacted Si nanoparticles were performed using SEM, TEM, EELS and FT-IR. The microstructures of as-made, core-shell nanoparticles of $\mathrm{Si}$ - Si boride are shown in Figure 1. The TEM image, Figure 1(a), clearly indicates the core-shell configuration with $\mathrm{Si}$ core $(\sim 150 \mathrm{~nm}$ diameter $)$ and a well defined and conformal Si boride shell (10 20 nm). The overall morphology and size distribution of Si boride-coated Si nanoparticles are depicted in the SEM image of Figure 1(b), which shows some distribution of the particle diameter of 50-200 nm, arising from the size distribution of the starting Si nanoparticles.

Shown in Figure 2 are TEM micrograph (Figure 2(a)) and the corresponding FFT pattern (Figure 2(b)) for the core-shell NPs with the annealed and passivated Si boride shell. The core is a polycrystalline silicon which is represented by main (111) crystal structure with P1 pattern as 
well as other crystalline structures such as Si (311) with P4 pattern, as shown in Figure 2(b). The shell is composed of the mixture of some crystalline phases (the inset in Figure 2(a)) including Si boride (P2, and P3 patterns in Figure 2(b)) and some amorphous phases including Si-B amorphous phase, borosilicate and silica which was formed during the annealing and shellpassivation procedure. The P2 pattern in Figure 2(b) has d-spacing of $2.8142 \AA$ which corresponds to the d-spacings of $\mathrm{SiB}_{3}(104), \mathrm{SiB}_{6}(260)$, or $\mathrm{SiB}_{6}(351)$ as summarized in the Table I. Another crystalline pattern, P3 in Figure 2(b) has d-spacing of $2.5633 \AA$ which is close to the d-spacings of $\mathrm{SiB}_{3}(113), \mathrm{SiB}_{3}(202), \mathrm{SiB}_{6}(162)$ or $\mathrm{SiB}_{6}(450)$.

EELS analysis was utilized to confirm the existence of boron as well as the composition in the shell of the core-shell nanoparticles. The diameter of Si-Si boride NP analyzed by EELS was approximately $80 \mathrm{~nm}$ in STEM image as indicated in Figure 3(a) where the shell thickness of the core-shell particle was about $10 \mathrm{~nm}$. The line scanning of EELS analysis was made for the region along $28 \mathrm{~nm}$ length along the direction from the core side (the core covered with shell) to the shell side (near the edge of the particle). Through this line-scanning in STEM mode, EELS spectrum could be measured for each Si and B, as shown in Figure 3(b). Line [I] in Figure 3(b) and (c) indicates the boundary between the shell-coated core region (the left side of line $[1]$ ) and pure shell region (the right side of line [I]). For the line scanning of the core part (the left side of line $[\mathrm{I}]$ in Figure 3(b)), the electron beam passes the top shell, Si core, and bottom shell of the spherical particle in that order. For the line scanning of the shell part (the right side of line [I] in Figure 3(b)), the beam goes through only the shell with progressively less material scanned as the beam moves out to the edge of the spherical particle.

The fractional compositions of core and shell in Si-Si boride NP were calculated (Figure 3(c)) using the EELS spectrum which had the counts of energy loss signal for every $1 \mathrm{~nm}$ step 
(Figure 3(b)). After a single spectrum (60 eV to $725 \mathrm{eV}$ ) was acquired at every $1 \mathrm{~nm}$, the many spectra were then converted into a line scan graph. The principal edge values of energy loss for each element, $99 \mathrm{eV}$ and $188 \mathrm{eV}$ were used to measure signals of Si and B element, respectively. The shell part is detected approximately from $17 \mathrm{~nm}$ to $28 \mathrm{~nm}$ on the Line Scan axis in Figure 3(b) and (c), if considering both STEM image and EELS spectrum. The core part is thought to be from $0 \mathrm{~nm}$ to $17 \mathrm{~nm}$ on the Line Scan axis, where both core material (Si) and shell materials ( $\mathrm{Si}$, and Si boride) exist.

It can be estimated from Figure 3(c) that the atom ratio of $\mathrm{Si} / \mathrm{B}$ in the shell part is 5/1 30/1, which means that B content is a smaller amount than Si in the overall area of the shell. In the phase diagram of $\mathrm{Si}-\mathrm{B}$ alloy, the alloy with $\mathrm{Si} / \mathrm{B}$ atom composition of 5/1 30/1 is composed of two phases including $\mathrm{Si}$ and $\mathrm{SiB}_{3}$ [29]. Therefore, the shell of the annealed Si-Si boride NPs is thought to consist of binary phases including crystalline $\mathrm{SiB}_{3}$ phase and Si phase except amorphous phasesas observed in TEM image and FFT pattern of Figure 2.

\subsection{Effect of Si Boride Shell on the Absorbance of IR Spectrum}

FT-IR measurement was made for the annealed Si - Si boride NPs and bare Si NPs in order to compare infrared (IR) absorbance behaviors of these two types of particles in relation with the effect of Si boride shell. Bare Si particles have the strong absorbance peaks in the region of 1100 $\sim 1000 \mathrm{~cm}^{-1}$ and $880 \sim 834 \mathrm{~cm}^{-1}$, as shown in Figure 4(a). The absorbance peak of $1100 \sim 1000$ $\mathrm{cm}^{-1}$ was reported for the vibration of Si-O bonding and the peak of $880 \sim 834 \mathrm{~cm}^{-1}$ results from the vibration of O-Si-O bonding [30]. The synthesized core-shell NPs display a new absorbance peak at $940 \mathrm{~cm}^{-1}$ and a new broad band composed of two peaks in the region of $777 \sim 677 \mathrm{~cm}^{-1}$, 
which are expected to be affected by boron-containing bonds of the Si boride shell formed by the diffusion of boron atoms into Si surface based on the following analysis.

As illustrated in Figure 4(b), the $\mathrm{SiB}_{3}$ and $\mathrm{SiB}_{6}$ particles have the main absorbance peaks in the range of $690 \sim 680 \mathrm{~cm}^{-1}$. The vibration band for B-B bonding was reported to occur approximately in the range of $1100 \sim 600 \mathrm{~cm}^{-1}$ [31]. One absorbance peak $\left(677 \mathrm{~cm}^{-1}\right)$ of the broad band $\left(777 \sim 677 \mathrm{~cm}^{-1}\right)$ for $\mathrm{Si}-\mathrm{Si}$ boride NPs matches with the main absorbance peaks of $\mathrm{SiB}_{3}\left(690 \sim 680 \mathrm{~cm}^{-1}\right)$ and $\mathrm{SiB}_{6}\left(690 \sim 680 \mathrm{~cm}^{-1}\right)$ particles. Si-O-B bonding was reported to have the absorbance peak in two wavenumbers of 930 and $680 \mathrm{~cm}^{-1}$ [30], which seems to represent a similar absorption behavior to that of the $\mathrm{Si}$ - Si boride NPs with the absorbance peaks $\left(940 \mathrm{~cm}^{-1}\right.$ and $677 \mathrm{~cm}^{-1}$ in Figure 4(a)). Also, B-O bonding was reported to make an absorption at the wavenumber of $1400 \mathrm{~cm}^{-1}$ [30], where the synthesized $\mathrm{Si}$ - Si boride NPs show the broad and weak absorbance peak, as can be seen in Figure 4(a). Based on this FT-IR analysis, it can be concluded that the new absorbance peaks of Si-Si boride NPs result from the formation of Si boride shell which is composed of boron-reacted materials including the forms of Si-B alloy ( $\mathrm{Si}$ boride), and $\mathrm{SiO}_{2}-\mathrm{B}_{2} \mathrm{O}_{3}$ (borosilicate).

\subsection{Improved Resistance to Thermal Oxidation}

The thermal oxidation resistance was measured with TGA in a pure oxygen atmosphere for $\mathrm{Si}$ - Si boride nanoparticles. The total weight gain of particles resulting from the thermal oxidation was compared to that of bare Si nanoparticles. We utilized accelerated oxidation method by using pure oxygen atmosphere at high temperatures.

Shown in Figure 5 are the comparative TGA analysis data showing the enhanced thermal oxidation resistance of the $\mathrm{Si}$ - Si boride core-shell NPs compared to the bare Si NPs. Thermal 
oxidation was measured based on the weight change of TGA during a temperature increasing step and a temperature holding step at $750{ }^{\circ} \mathrm{C}$ (Figure 5(a)) and $850{ }^{\circ} \mathrm{C}$ (Figure 5(b)). These accelerated oxidation tests in pure oxygen atmosphere by TGA indicate that the core-shell Si-Si boride NPs with boron-alloyed shells exhibit a much higher resistance to thermal oxidation than bare Si NPs. After holding at $750{ }^{\circ} \mathrm{C}$ for $2 \mathrm{hrs}$ in TGA test, the core-shell NPs had a much smaller amount of weight gain (3.2 wt\%) by a factor of 4.6 compared to that of bare Si NPs (14.6 wt\%). Similarly as for the $750{ }^{\circ} \mathrm{C}$ TGA, the $850{ }^{\circ} \mathrm{C}$ TGA results also indicate that the weight gain $(9.4$ $\mathrm{wt} \%$ ) of the core-shell nanoparticles decreased much by a factor of 3.5 in comparison to bare $\mathrm{Si}$ NPs (33 wt \%), after the temperature holding step of $850^{\circ} \mathrm{C} / 2 \mathrm{hrs}$.

This significantly enhanced oxidation resistance of the core-shell structured $\mathrm{Si}$ - Si boride NPs results from the contribution of the conformally present shell layer which consists of crystalline $\mathrm{Si}$ borides $\left(\mathrm{SiB}_{3}\right.$, or $\left.\mathrm{SiB}_{6}\right)$ and other vitreous phases including borosilicate. From the previously reported researches, it can be expected that crystalline $\beta-\mathrm{SiB}_{3}$ [15], and vitreous borosilicate layer [16-19] helps to decrease oxidation rate. The reduced oxidation data clearly indicates that the oxygen diffusion through the Si boride shell layer in the core-shell NPs is significantly slower than through the pure Si material.

\subsection{Optical Properties of SSC Layers}

High temperature applications of semiconductors are receiving more attention these days, for example, more efficient solar cells and thermoelectric devices using concentrated/focused sunlight with the naturally higher operating temperatures [8-10]. Therefore, high temperature oxidation resistant coating on a semiconductor surface is generally desirable. While the main focus of this research is on the improved oxidation resistance of Si based semiconductor 
nanomaterials at high temperatures for potential applications to a variety of devices, one example of the such possible applications of the surface-protected Si nanoparticles is for efficient sunlight absorption in the Concentrating Solar Power (CSP) power generating systen. Therefore, the optical reflection measurement was made on SSC layers composed of Si - Si boride NPs coated on Inconel substrate and exposed to high temperatures, as compared to bare Si NPs processed in a similar manner.

The reflection measurement was made with the form of spectrally selective coating (SSC) layer composed of Si - Si boride NPs and another Si NPs casted on Inconel substrate as shown in Figure 6 in order to compare the thermal stability of optical property based on the reflection measurement with annealing at high temperature in air atmosphere.

As can be seen in Figure 6, the prepared SSC layers with Si-Si boride NPs exhibits very little change in the surface color from the initial dark brown for as-prepared sample even after they were exposed to $850^{\circ} \mathrm{C}$ annealing for $10 \mathrm{hrs}$ in air. This implies that the $\mathrm{Si}$ - $\mathrm{Si}$ boride NPs can provide a strong resistance to thermal oxidation. On the contrary, SSC layers made of bare $\mathrm{Si}$ NPs have quite an obvious change of surface color from the intial light brown to orange color when exposed to $850{ }^{\circ} \mathrm{C}$ for $5 \mathrm{hrs}$, then to nearly white color after exposure to $850{ }^{\circ} \mathrm{C}$ for $10 \mathrm{hrs}$ (Figure 6). These changes to lighter colors are caused by easy oxidation of bare Si NPs at high temperature in air.

Figure 7 shows the comparison of the optical reflectance between the SSC layer of $\mathrm{Si}-\mathrm{Si}$ boride NPs and that of Si NPs. As shown in Figure 7(a), from long to short wavelengths, the reflectance starts decreasing abruptly at the wavelength of $1.05 \sim 1.08 \mu \mathrm{m}$, corresponding to bandgap of $\mathrm{Si}(1.13 \mu \mathrm{m}$ or $1.12 \mathrm{eV})$ [32], and continues to reduce more gradually to $400 \mathrm{~nm}$ in the visible spectrum. If the transition point of reflectance is defined as the cut-off wavelength of 
reflection, it can be analyzed from Figure 7(a) that the cut-off point of SSC layers with $\mathrm{Si}$ - Si boride NPs remains stable near the wavelength regime of $1.05 \sim 1.08 \mu \mathrm{m} \mu \mathrm{m}$ even though the reflectance in the near-IR regime was somewhat affected by the high temperature exposure, with the reflectance after 10 hours exposure at $800^{\circ} \mathrm{C}$ stabilizing toward the original value in the asmade samples (further research is required for understanding of specific effects of high temperature annealing parameters). Compared to the stable cut-off wavelength behavior of the SSC layer comprising the surface-protected Si NPs, the SSC layer with bare Si NPs exhibits a profound change upon $850^{\circ} \mathrm{C}$ exposure, with the cut-off wavelength becoming significantly shorter from 1.05 1.08 um in the near IR regime to $645 \mathrm{~nm}$ in the visible spectrum regime as shown in Figure 7(b). After annealing at $850^{\circ} \mathrm{C}$, the reflectance of visible spectrum in SSC layers with Si - Si boride NPs are much more stable than that with bare Si NPs which experiences more increment of reflectance with annealing time increasing as shown in Figure 7(b). This implies that most part of the bare $\mathrm{Si} \mathrm{NP}$ was transformed into an insulating $\mathrm{SiO}_{2}$ phase upon exposure to $850^{\circ} \mathrm{C}$ for $10 \mathrm{hrs}$ in air atmosphere in agreement with the color changes shown in Figure 6.

While further R\&D will be required to optimize the surface protection structures and their behavior, the sunlight receiver made of SSC layers with surface-protected Si - Si boride type NPs can be expected to enable a more stable/reliable electricity generation during high temperature operation in various solar thermal applications than with pure surface-unprotected semiconductor materials. Furthermore, the reflectance values in the visible spectrum representing a greater amount of sunlight energy is substantially lower in SSC layers with $\mathrm{Si}$ - Si boride NPS than that with bare Si NPs, which also allows much more efficient sunlight absorption so as to reach higher thermal efficiency. 


\section{Summary}

The present study reports a new fabrication method to make conformal, surface-protecting Si boride nanoshell on Si nanoparticles, and associated microstructural and optical properties. The 10 20 nm thick uniform coating of Si boride shell was formed by reacting surface atoms of Si nanoparticles with a molten salt of sodium borohydride. The presence of the Si boride shell was confirmed by TEM, EELS and FT-IR analyses. Based on the TGA analysis, it was found that the boride-coated core-shell Si nanoparticles exhibit remarkably improved resistance to thermal oxidation by a factor of 4.6 at $750{ }^{\circ} \mathrm{C}$ and 3.5 at $850{ }^{\circ} \mathrm{C}$. Optical measurements show that spectrally selective coating (SSC) layer of Si - Si boride NPs has superior optical stability and lower reflectance compared to that of bare Si NPs after exposure to $850{ }^{\circ} \mathrm{C}$ annealing, exhibiting a significantly higher absorption in the visible spectrum range. These surface-protected, oxidation-resistant semiconductor materials and their novel synthesis methods can be useful for various high temperature solar thermal or solar electric applications.

\section{Acknowledgements}

The support of this research by Department of Energy through DOE SunShot Project (DEEE0005802) and by University of California Proof of Concept Award ID\# 12-PC-246854 are acknowledged. 


\section{References}

[1] A. Lenert, D. M. Bierman, Y. Nam, W. R. Chan, I. Celanovic, M. Soljacic, E. N. Wang, Nature Nanotechnology 9 (2014) 126-130.

[2] D. E. Carlson, C. R. Wronski, Appl. Phys. Lett. 28 (1976) 671-673.

[3] A. G. Aberle, Prog. Photovolt : Res. Appl. 8 (2000) 473-487.

[4] R. N. Dominey, N. S. Lewis, J. A. Bruce, D. C. Bookbinder, M. S. Wrighton, J. Am. Chem. Soc. 104 (1982) 467-482.

[5] Y. Cui, Z. Zhong, D. Wang, W. U. Wang, C. M. Lieber, Nano Lett. 3 (2003) 149-152.

[6] G. W. Meethan, J. Mater. Sci. 26 (1991) 853-860.

[7] C. E. Kennedy, Review of Mid to High Temperature Solar Selective Absorber Materials, NREL Technical Report, NREL/TP-520-31267, 2002.

[8] D. Kraemer, B. Poudel, H.-P. Feng, J. C. Caylor, B. Yu, X. Yan, Y. Ma, X. Wang, D. Wang, A. Muto, K. McEnaney, M. Chiesa, Z. Ren, G. Chen, Nature Materials 10 (2011) 532-538.

[9] M. Jang, Y. Park, M. Jun, Y. Hyun, S.-J. Choi, T. Zyung, Nanoscale Res. Lett. 5 (2010) 1654-1657.

[10] L. L. Baranowski, G. J. Snyder, E. S. Toberer, Energy Environ. Sci. 5 (2012) 9055-9067.

[11] B. E. Deal, A. S. Grove, J. Appl. Phys. 36 (1965) 3770-3778.

[12] L. Kaufman, in: J. T. Waber, P. Chiotti, W. N. Miner (Eds.), Compounds of Interest in Nuclear Reactor Technology, AIME, New York, 1964, pp.193.

[13] M. M. Opeka, I. G. Talmy, J. A. Zaykoski, J. Mater. Sci. 39 (2004) 5887-5904.

[14] R. G. Munro, J. Res. NIST 105 (2000) 709-720.

[15] J. R. Salvador, D. Bilc, S. D. Mahanti, M. G. Kanatzidis, Angew. Chem. Int. Ed. 42 (2003) 1929-1932. 
[16] P. C. Innocenzi, M. Guglielmi, M. Gobbin, P. Colombo, J. the European Ceramic Society 10 (1992) 431-436.

[17] M. Guglielmi, D. Festa, P.C. Innocenzi, P. Colombo, M. Gobbin, J. Non-Crystalline Solids $147 \& 148$ (1992) 474-477.

[18] J. A. Lemberg, R. O. Ritchie, Adv. Mater. 24 (2012) 3445-3480.

[19] K. Kobayashi, K. Maeda, H. Sano, Y. Uchiyama, Carbon 33 (1995) 397-403.

[20] H. Moissan, A. Stock, C. R. Acad. Sci.(Paris) 131 (1900) 139.

[21] C. F. Cline, Nature 181 (1958) 476-477.

[22] E. Colton, J. Am. Chem. Soc. 82 (1960) 1002.

[23] C. Brosset, B. M, Nature 187 (1960) 54-55.

[24] H. F. Rizzo, L. R. Bidwell, J. Am. Cera. Soc. 43 (1960) 550-552.

[25] T. Goto, M. Mukaida, T. Hirai, Mater. Res. Soc. Symp. Proc. 168 (1990) 167-172.

[26] J. R. A. Carlsson, X.-H. Li, S. F. Gong, H. T. G. Hentzell, J. Appl. Phys. 74 (1993) 891896.

[27] Y. Filinchuk, A. V. Talyzin, D. Chernyshov, V. Dmitriev, Phys. Rev. B 76 (2007) $092104-$ 1-092104-4.

[28] J. Urgnani, F.J. Torres, M. Palumbo, M. Baricco, International J. Hydrogen Energy 33 (2008) 3111-3115.

[29] R. W. Olesinski, G. J. Abbaschian, Bulletin of Alloy Phase Diagrams 5 (1984) 478-484.

[30] K. Murase, T. Ogino, Y. Mizushima, Japanese J. Appl. Phys 22 (1983) 1771-1777.

[31] G. -R. Yang, Y. -P. Zhao, B. Y. Tong, Mat. Res. Soc. Symp. Proc. 426 (1996) 83-88.

[32] S. M. Sze, Physics of Semiconductor Devices, 2nd Ed., Wiley, New York, 1981, pp.15. 


\section{Figure Captions}

Figure 1. Microstructural images of as-made $\mathrm{Si}$ - Si boride core-shell nanoparticles ; (a) TEM image showing 10 $20 \mathrm{~nm}$ thick Si boride shell, and (b) lower mag SEM image of overall coreshell nanoparticles.

Figure 2. (a) TEM image near the shell area of a Si - Si boride core-shell nanoparticle with the inset showing the lattice image taken from red-lined square area in the shell area (lower right in Figure 2 (a)), and (b) corresponding FFT patterns for the image (a) showing some crystal phases $(\mathrm{P} 2, \mathrm{P} 3$ in (b)).

Figure 3. (a) STEM image showing the line-scan part (green line, spectrum image) of EELS in the core-shell Si - Si boride NPs, (b) EELS spectrum showing the counts of energy loss signal for each element ( $\mathrm{Si}$ and $\mathrm{B}$ ) on line-scanning from the core side to the shell side, and (c) the composition of core side and shell side in $\mathrm{Si}-\mathrm{Si}$ boride core-shell nanoparticle, calculated from the EELS spectrum.

Figure 4. FT-IR analysis showing (a) $\mathrm{Si}$ - $\mathrm{Si}$ boride NPs have new absorbance peaks containing a broad band with two peaks of $777 \sim 677 \mathrm{~cm}^{-1}$ and another peak of $940 \mathrm{~cm}^{-1}$ compared to bare Si NPs, and (b) the main absorbance is made at $690-680 \mathrm{~cm}^{-1}$ for $\mathrm{SiB}_{3}$, and $\mathrm{SiB}_{6}$ material.

Figure 5. Accelerated TGA analysis comparing bare Si nanoparticles to the surface-protected, core-shell structured $\mathrm{Si}$ - Si boride nanoparticles ( $\mathrm{Si}-\mathrm{B}),(\mathrm{a})$ at $750{ }^{\circ} \mathrm{C}$, and (b) at $850{ }^{\circ} \mathrm{C}$ in pure oxygen atmosphere.

Figure 6. Surface color change of SSC layers after annealing at $850{ }^{\circ} \mathrm{C}$ with the high temperature exposing time increasing up to $10 \mathrm{hrs}$ under air atmosphere.

Figure 7. Reflectance measurements of high temperature exposed SSC layers made of (a) Si - Si boride NPs (Si-B), and (b) bare Si NPs.

Table 1. Summary table for the possible crystal structures for core and shell calculated from the FFT patterns in Figure 2(b).

\begin{tabular}{lcll}
\hline & FFT Patterns & d-spacing & Crystal Structures \\
\hline Core $(\mathrm{Si})$ & $\mathrm{P} 1$ & $3.1755 \AA$ & $\mathrm{Si}(111)$ \\
& $\mathrm{P} 4$ & $1.5983 \AA$ & $\mathrm{Si}(311)$ \\
& & & \\
Shell (Si boride) & $\mathrm{P} 2$ & $2.8142 \AA$ & $\mathrm{SiB}_{3}(104), \mathrm{SiB}_{6}(260), \mathrm{SiB}_{6}(351)$ \\
& $\mathrm{P} 3$ & $2.5633 \AA$ & $\mathrm{SiB}_{3}(113), \mathrm{SiB}_{3}(202), \mathrm{SiB}_{6}(162)$, \\
& & & $\mathrm{SiB}_{6}(450)$
\end{tabular}



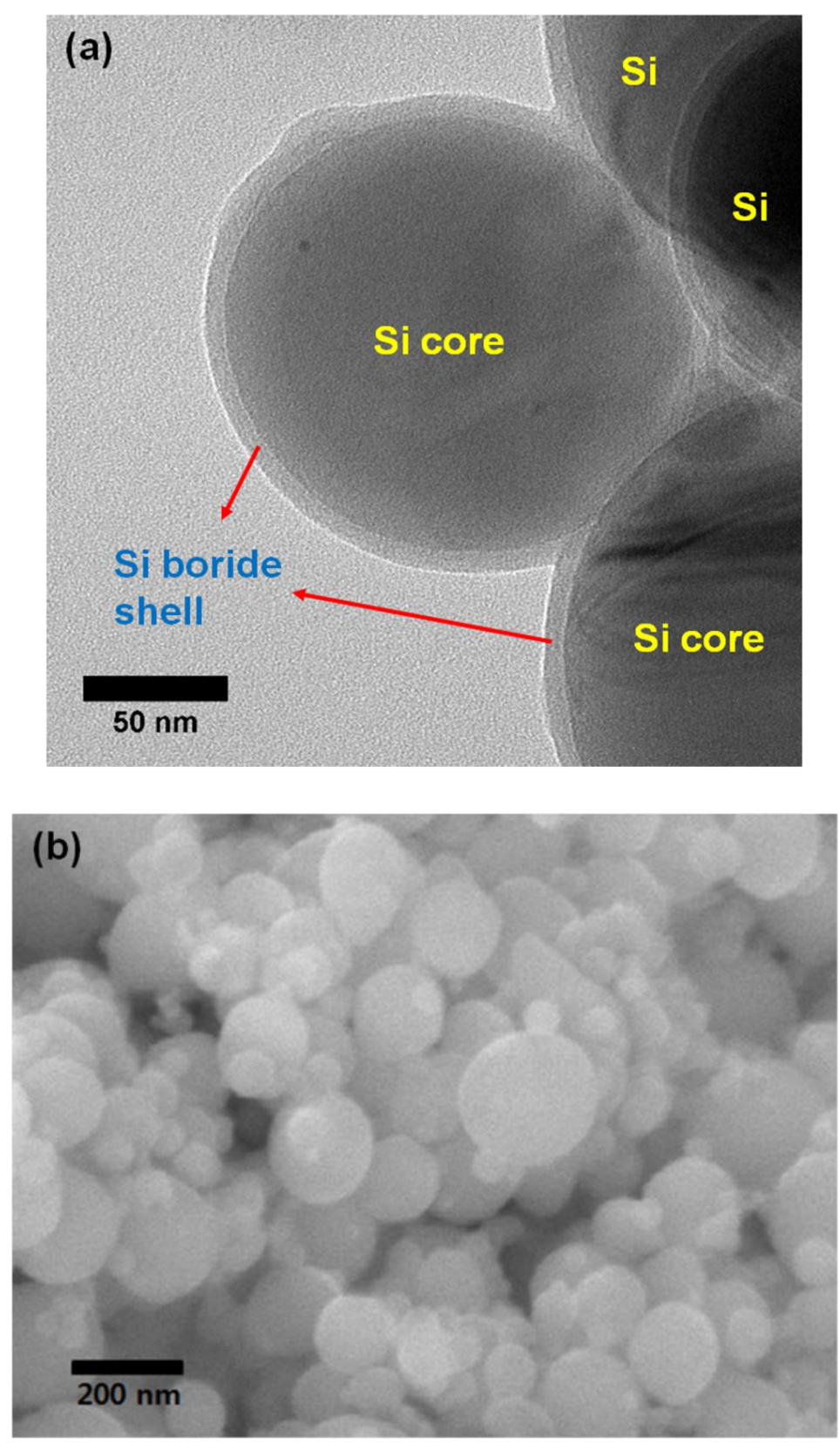

Figure 1. Microstructural images of as-made $\mathrm{Si}$ - Si boride core-shell nanoparticles ; (a) TEM image showing 10 20 nm thick Si boride shell, and (b) lower mag SEM image of overall coreshell nanoparticles. 


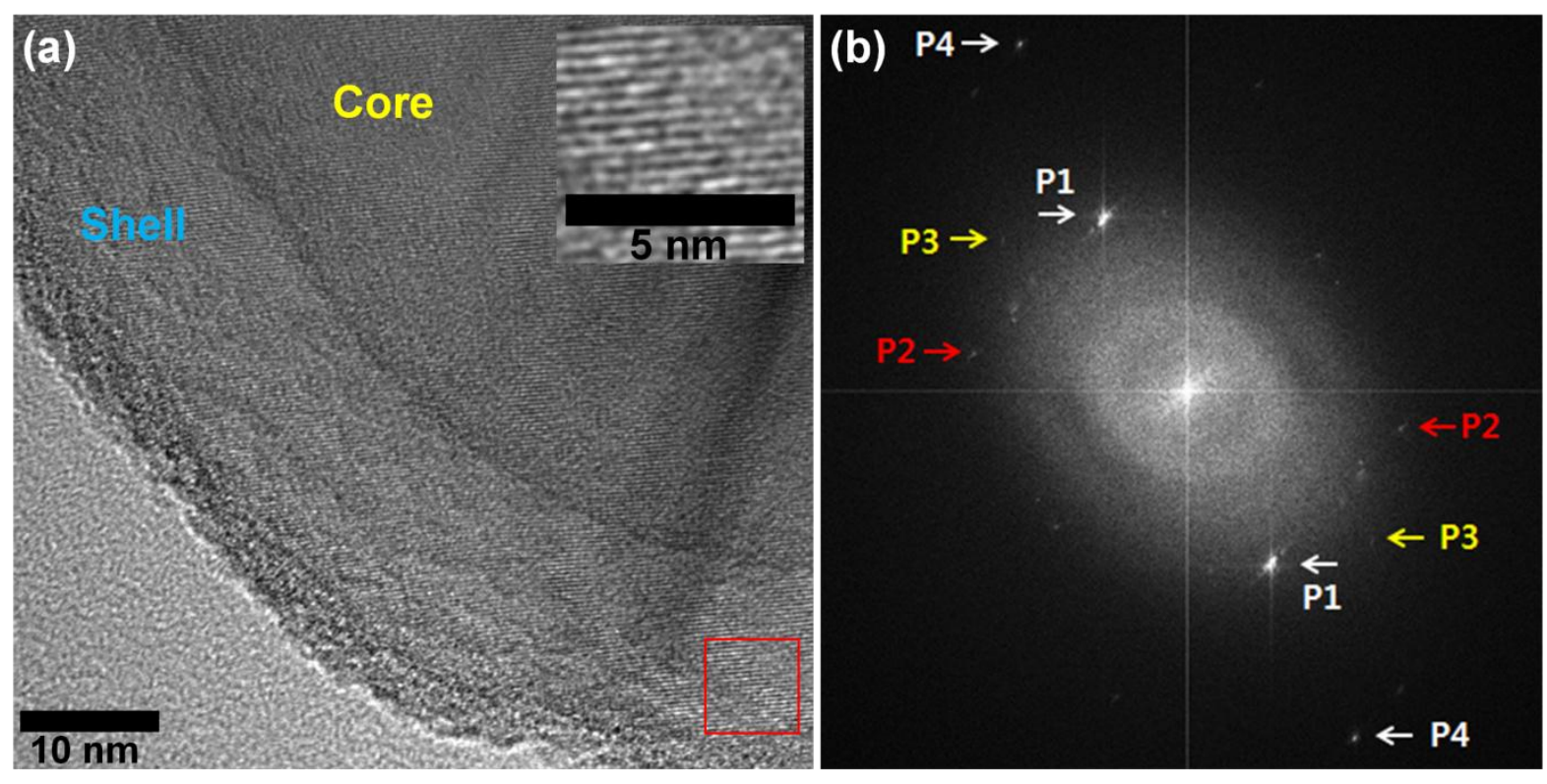

Figure 2. (a) TEM image near the shell area of a $\mathrm{Si}$ - Si boride core-shell nanoparticle with the inset showing the lattice image taken from red-lined square area in the shell area (lower right in Figure 2(a)), and (b) corresponding FFT patterns for the image (a) showing some crystal phases (P2, P3 in (b)).

(a)

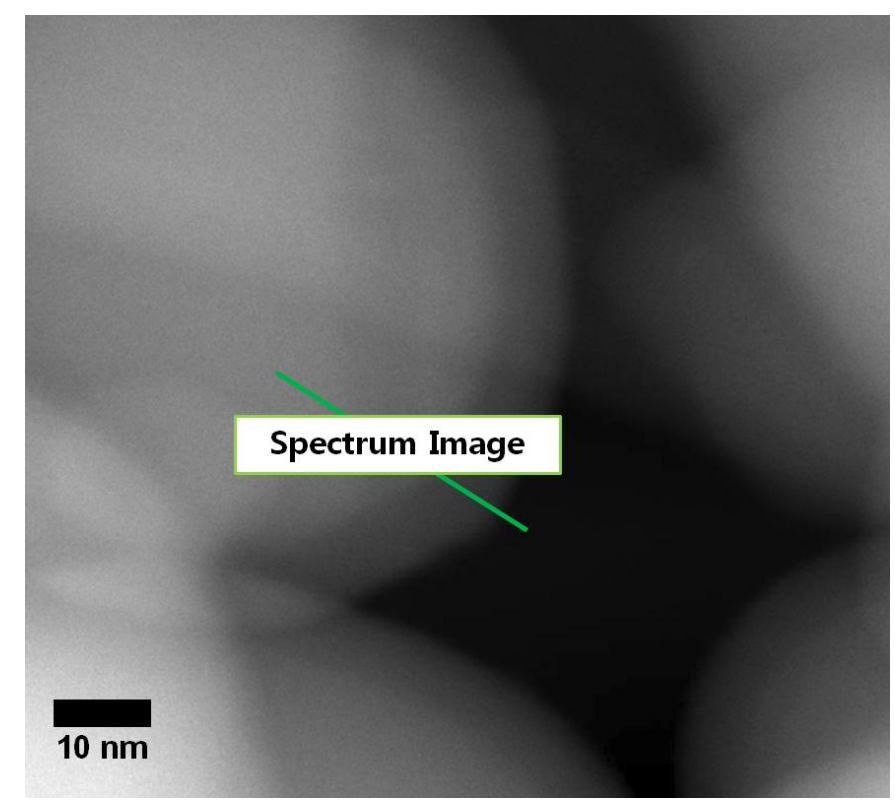


(b)

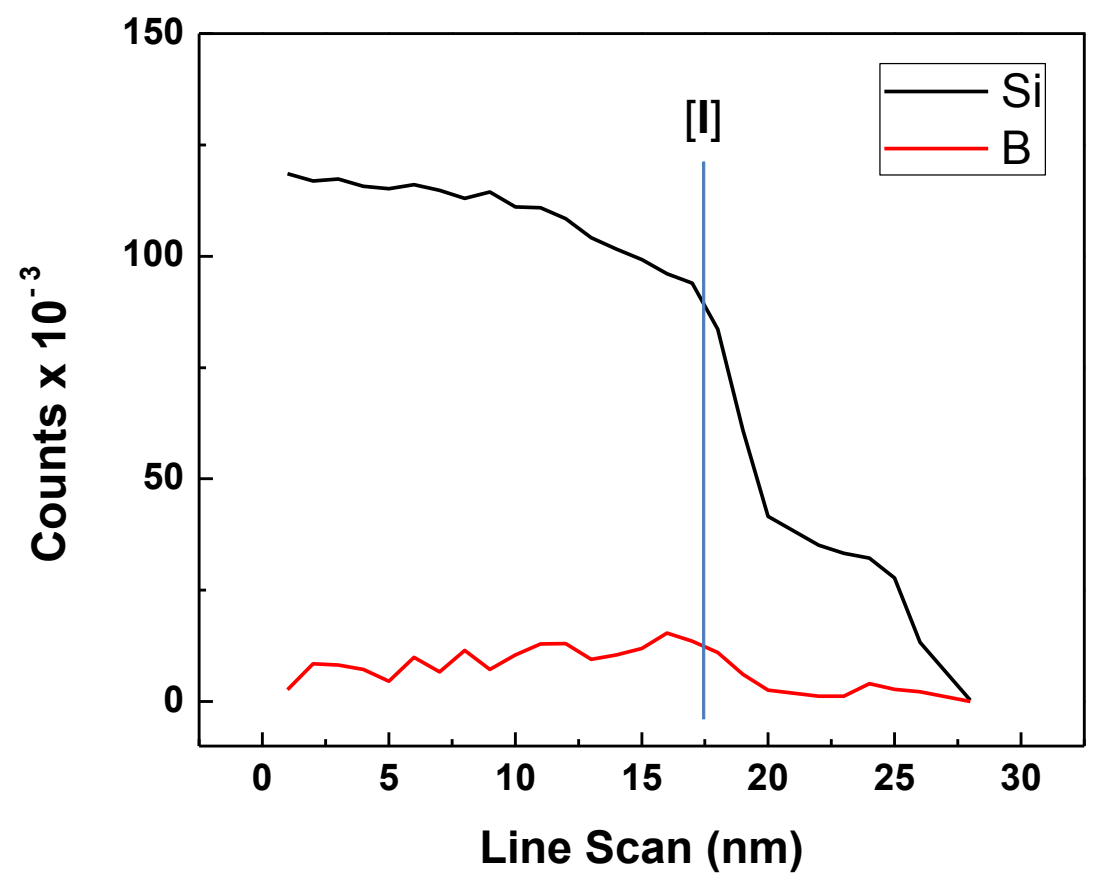

(c)

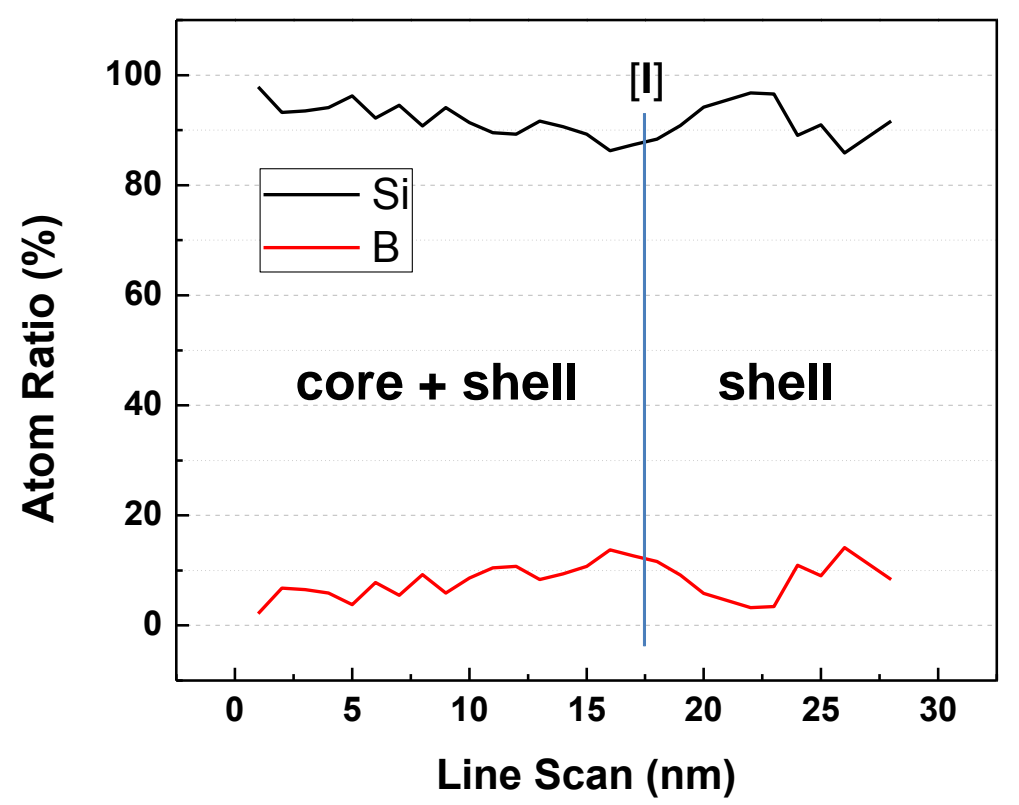

Figure 3. (a) STEM image showing the line-scan part (green line, spectrum image) of EELS in the core-shell Si - Si boride NPs, (b) EELS spectrum showing the counts of energy loss signal for each element ( $\mathrm{Si}$ and $\mathrm{B}$ ) on line-scanning from the core side to the shell side, and (c) the composition of core side and shell side in $\mathrm{Si}$-Si boride core-shell nanoparticle, calculated from the EELS spectrum. 
(a)

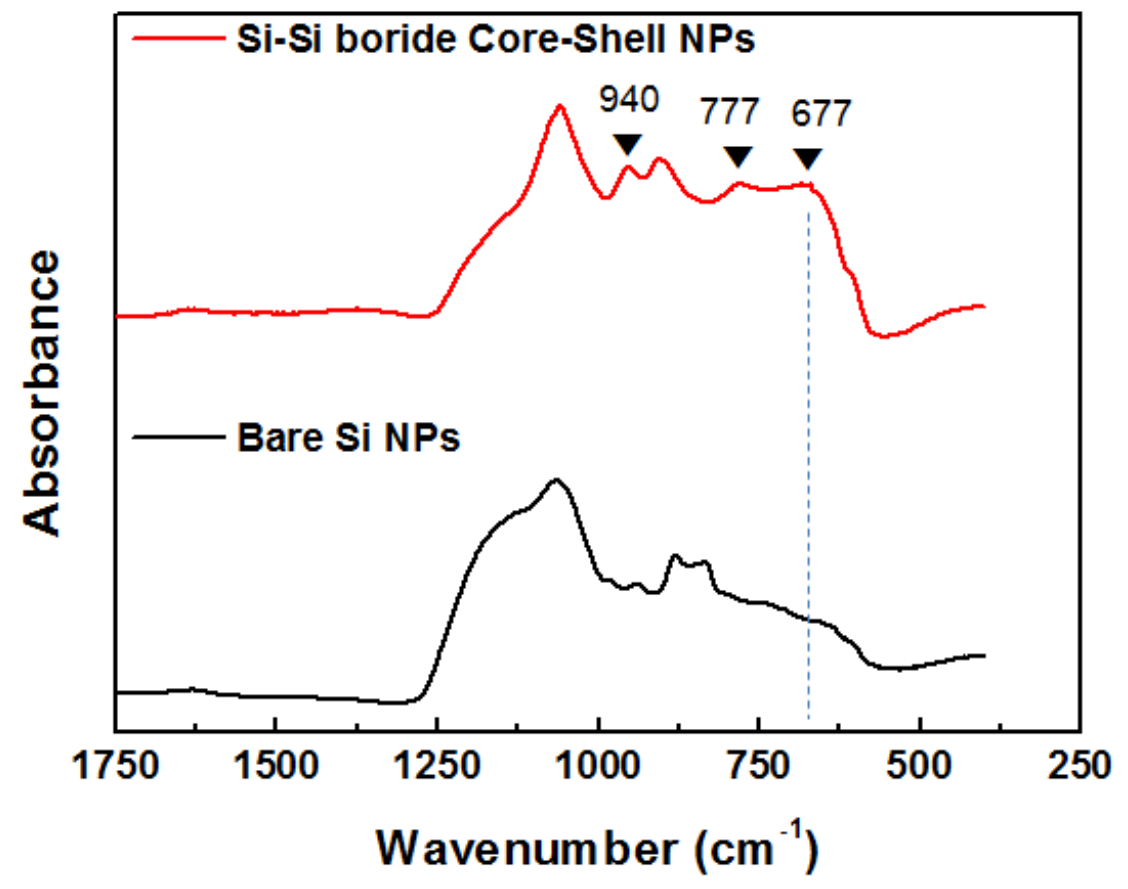

(b)

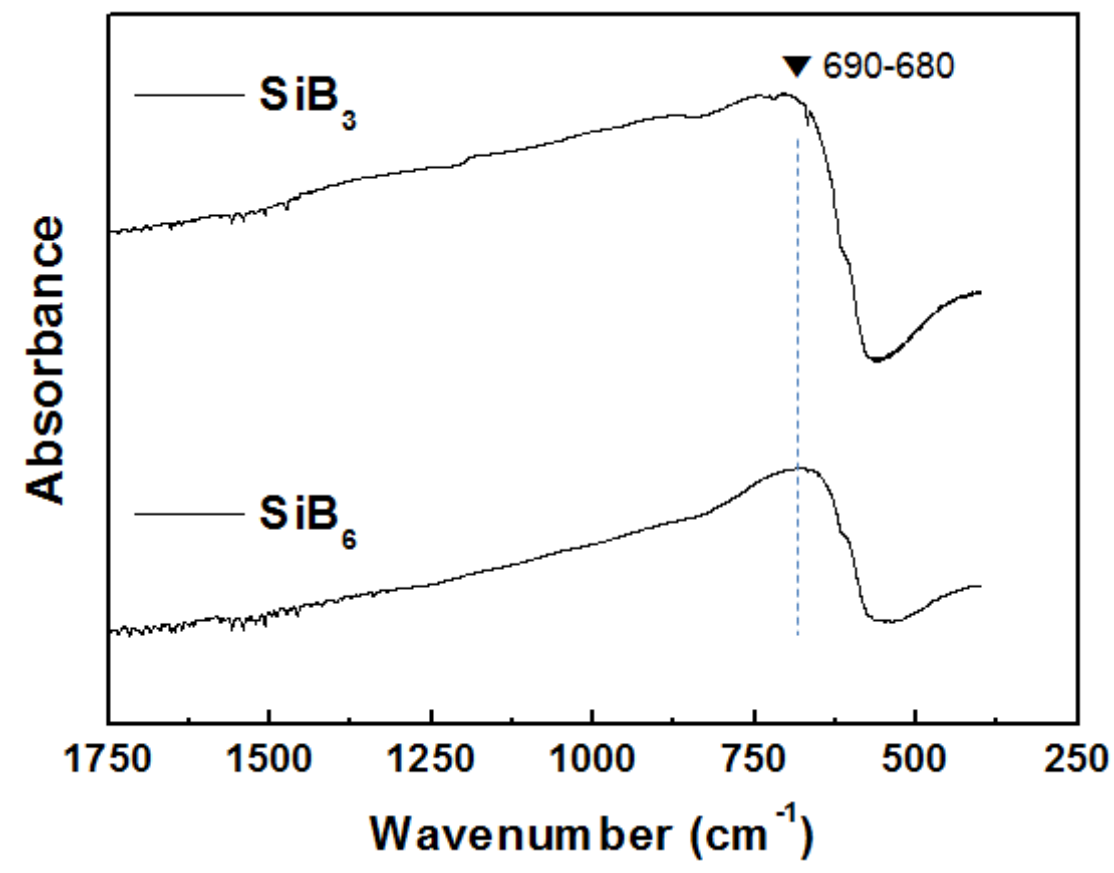

Figure 4. FT-IR analysis showing (a) $\mathrm{Si}$ - Si boride NPs have new absorbance peaks containing a broad band with two peaks of $777 \sim 677 \mathrm{~cm}^{-1}$ and another peak of $940 \mathrm{~cm}^{-1}$ compared to bare Si NPs, and (b) the main absorbance is made at $690-680 \mathrm{~cm}^{-1}$ for $\mathrm{SiB}_{3}$, and $\mathrm{SiB}_{6}$ material. 
(a)

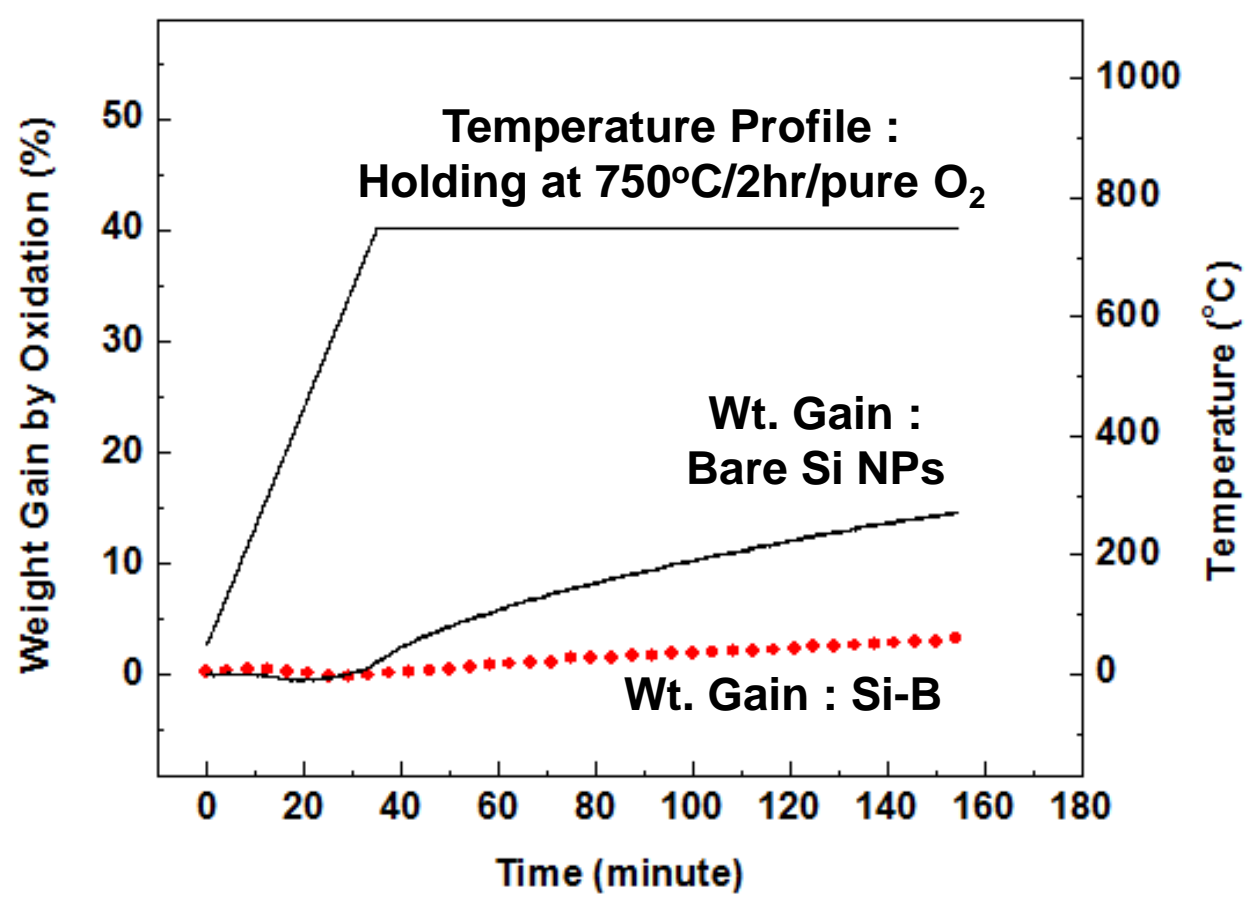

(b)

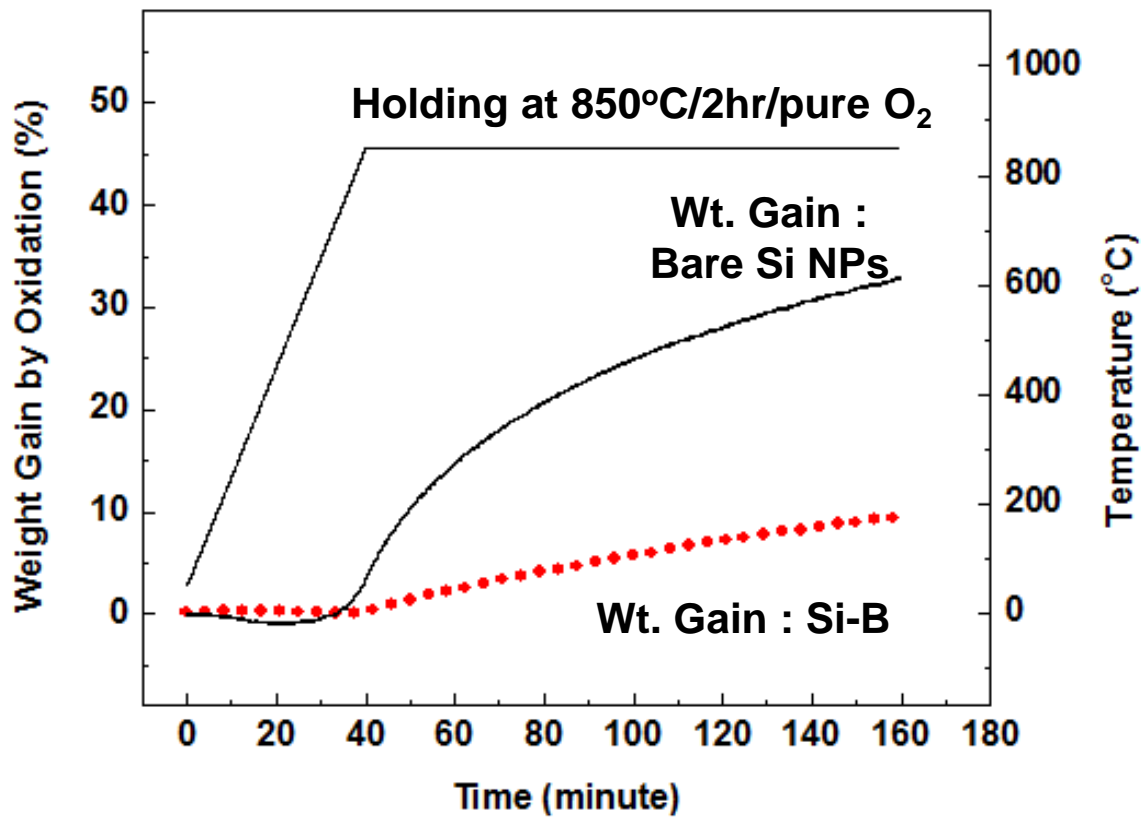

Figure 5. Accelerated TGA analysis comparing bare Si nanoparticles to the surface-protected, core-shell structured $\mathrm{Si}$ - Si boride nanoparticles ( $\mathrm{Si}-\mathrm{B}),(\mathrm{a})$ at $750{ }^{\circ} \mathrm{C}$, and (b) at $850{ }^{\circ} \mathrm{C}$ in pure oxygen atmosphere. 


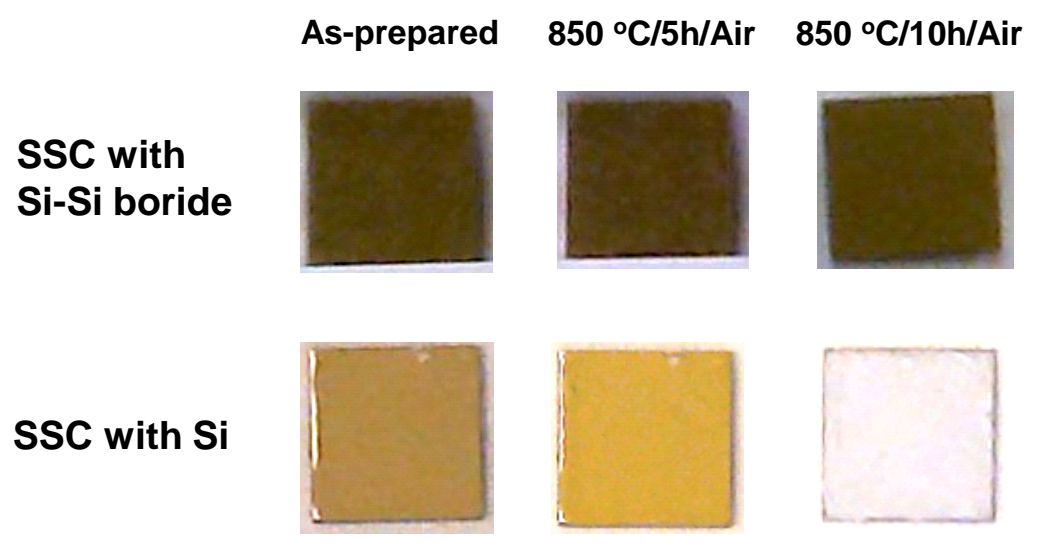

Figure 6. Surface color change of SSC layers after annealing at $850{ }^{\circ} \mathrm{C}$ with the high temperature exposing time increasing up to $10 \mathrm{hrs}$ under air atmosphere. 


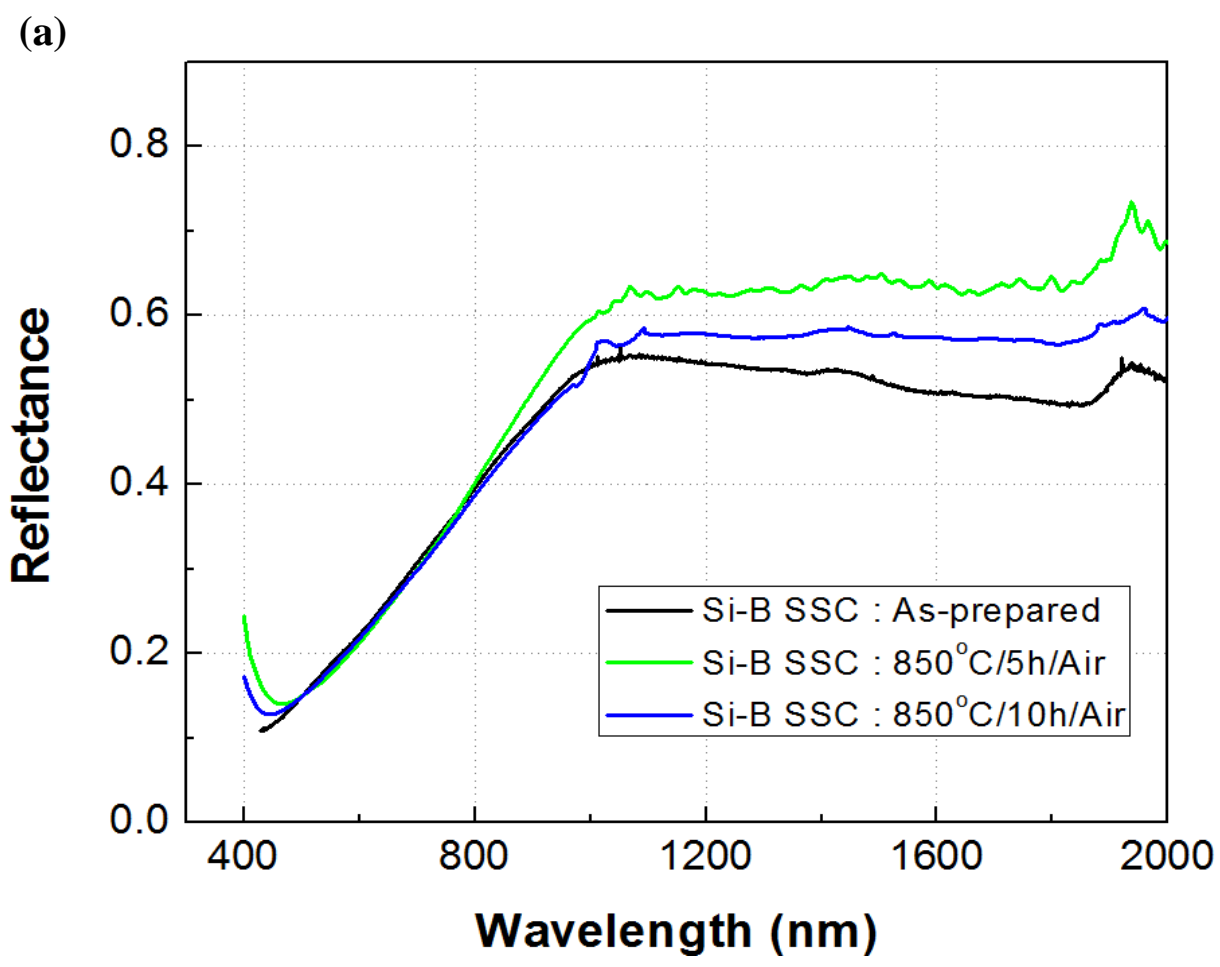

(b)

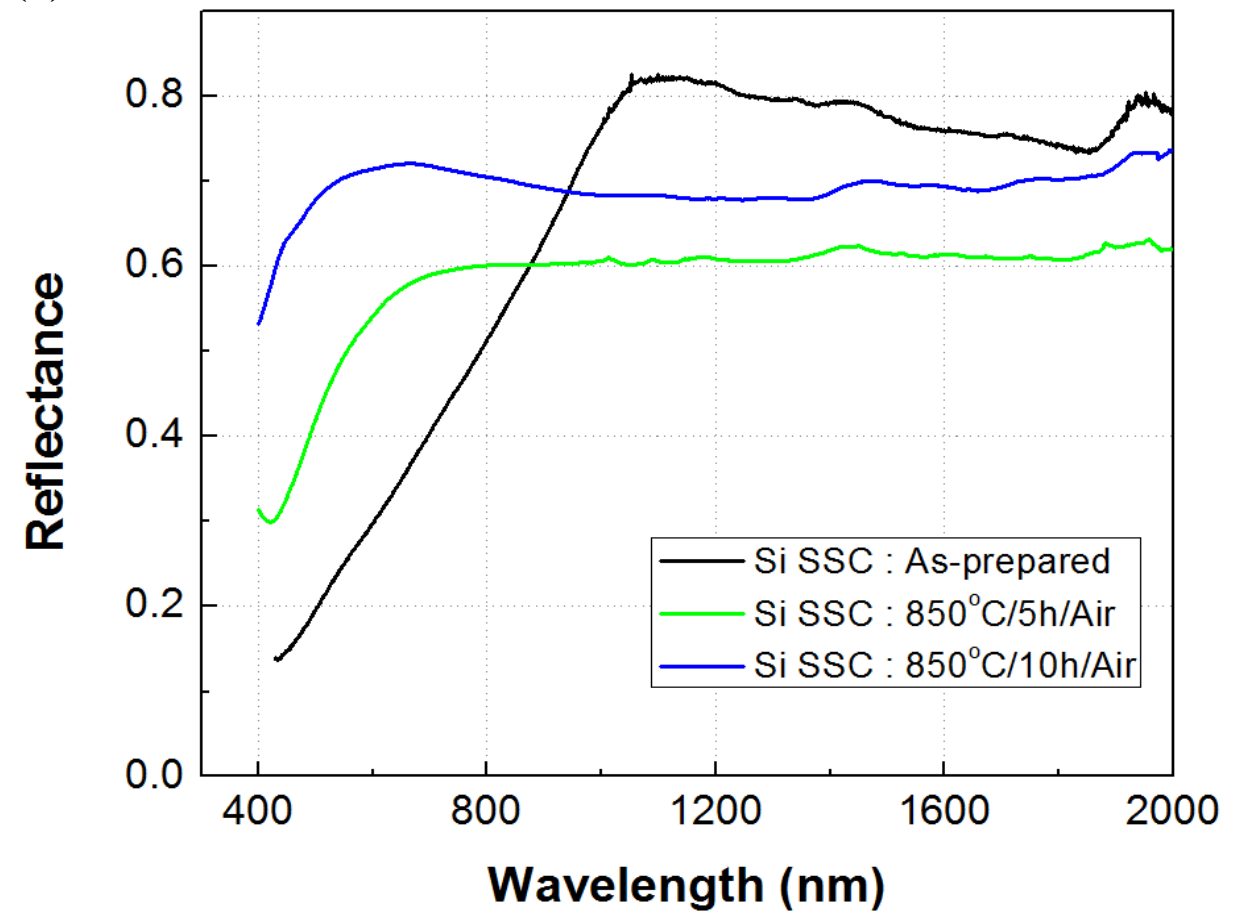

Figure 7. Reflectance measurements of high temperature exposed SSC layers made of (a) Si - Si boride NPs (Si-B), and (b) bare Si NPs. 


\section{Graphical Abstract}
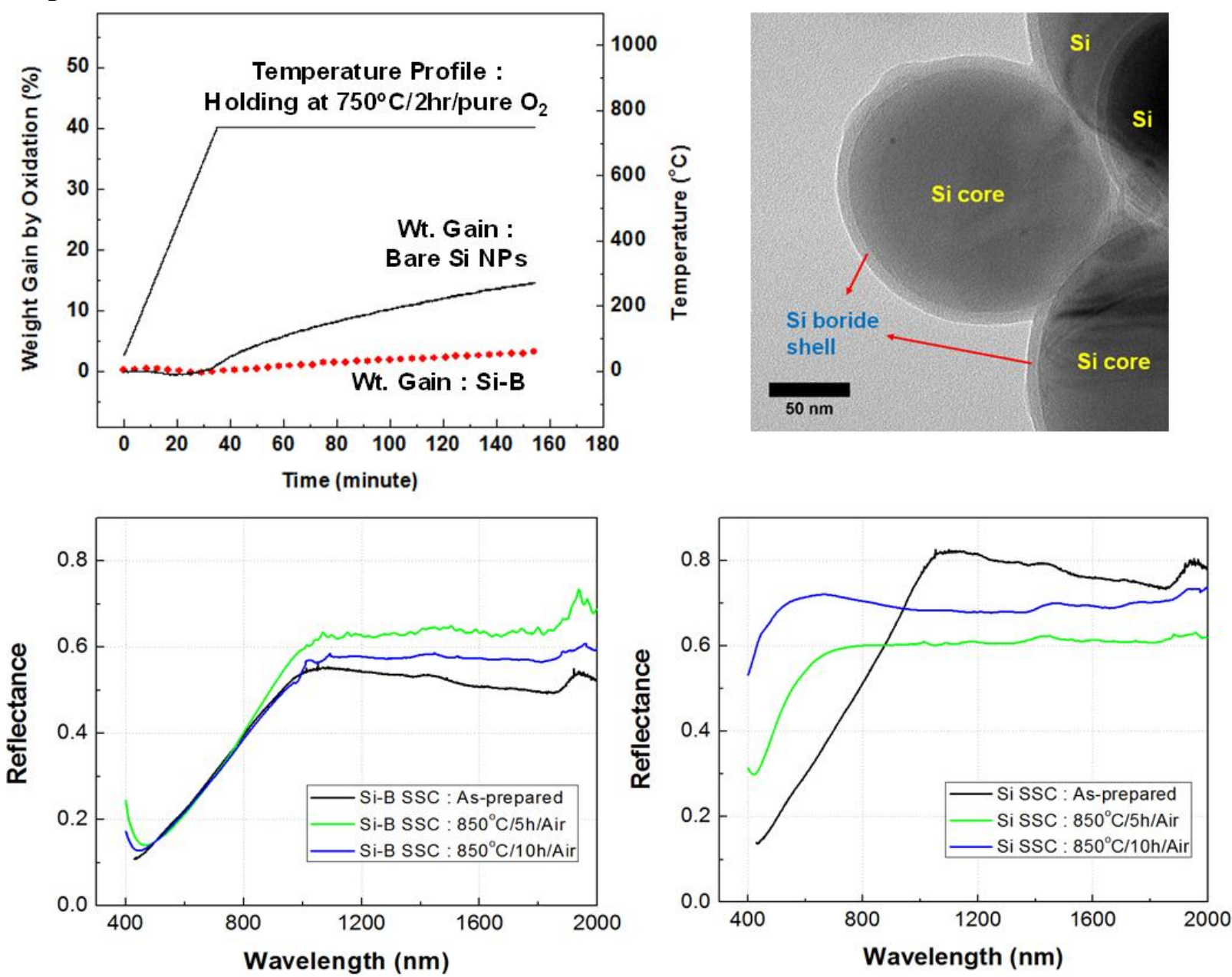